\title{
Love is in the air: olfaction-based mate-odour identification by jumping spiders from the genus $\mathrm{Cy}$ rba
}

\author{
Ana M. Cerveira $\cdot$ Robert R. Jackson
}

Received: 19 March 2012/Accepted: 27 August 2012/Published online: 19 September 2012

(C) Japan Ethological Society and Springer 2012

\begin{abstract}
Jumping spiders (Salticidae) are known for having good eyesight, but the extent to which they rely on olfaction is poorly understood. Here we demonstrate for the first time that olfactory pheromones are used by two species from the salticid genus Cyrba (C. algerina and C. ocellata). Using a Y-shape olfactometer, we investigated the ability of adult males and females of both species to discriminate between mate and non-mate odour. A hidden spider or a spider's draglines (no spider present) were used as odour sources. There was no evident response by females of either Cyrba species to any tested odour. Males of both species chose odour from conspecific females, or their draglines, significantly more often than the no-odour control, but there was no evident response by males to any of the other odours (conspecific male and heterospecific female). Our findings demonstrate that C. algerina and C. ocellata males can make sex- and species-specific discriminations even when restricted to using olfaction alone. Also, by showing that draglines can be a source of olfactory pheromones, our findings illustrate
\end{abstract}

A. M. Cerveira · R. R. Jackson

School of Biological Sciences, University of Canterbury,

Private Bag 4800, Christchurch 8140, New Zealand

e-mail: robert.jackson@ canterbury.ac.nz

Present Address:

A. M. Cerveira ( $\square)$

Centre for Environmental and Marine Studies (CESAM),

Departamento de Biologia Animal, Faculdade de Ciências,

Universidade de Lisboa, Edif. C2, Campo Grande,

1749-016 Lisbon, Portugal

e-mail: ana.cerveira@gmail.com

R. R. Jackson

International Centre of Insect Physiology and Ecology (ICIPE),

Thomas Odhiambo Campus, P.O. Box 30, Mbita Point, Kenya the difficulty of ruling out olfaction when attempting to test for chemotactile cues.

Keywords Olfaction - Mate identification . Mating systems $\cdot$ Pheromones $\cdot$ Salticidae

\section{Introduction}

Specific compounds or blends of compounds, known as pheromones, often function as signals that mediate interactions between conspecific individuals (Shorey 1976; Maynard Smith and Harper 2003; Carde and Millar 2004; Bradbury and Vehrenchamp 2011). Perhaps all animals rely to some extent on chemoreception (Wyatt 2003; Steiger et al. 2011), but the literature is dominated by research on insects, with spiders being comparatively neglected. Symonds and Elgar (2008) have estimated that about $80 \%$ of all pheromone research has been on insects, whereas only about $1 \%$ has been on spiders.

With spiders, as with animals in general, it is customary to distinguish between contact-chemoreception (chemotactile) and olfactory pheromones (Barth 2001; Foelix 2011), but most experiments pertaining to pheromone use by spiders have allowed for contact with webs, nests or silk draglines (Trabalon and Bagnères 2010), leaving unresolved the question of whether chemotactile or olfactory pheromones, or both, mediated the spider's response. A more limited number of studies have been based on testing design that ruled out contact and thereby showed that specifically olfaction mediated the spider's response (Blanke 1972; Schulz and Toft 1993; Searcy et al. 1999; Papke et al. 2000, 2001; Gaskett 2007; Cross and Jackson 2009a; Aisenberg et al. 2010; Jerhot et al. 2010; Chinta et al. 2010; Xiao et al. 2010). 
As a step toward a fuller understanding of olfactory communication by spiders, we investigated Cyrba algerina and $C$. ocellata, two species from the family Salticidae. Although salticids are better known for their unique eyes and complex vision-based behaviour (Land and Nilsson 2002; Jackson and Cross 2011a; Harland et al. 2012), numerous studies have illustrated the use of acoustic, percussive (seismic), silk-borne and tactile signalling during salticid intraspecific interactions (Edwards 1981; Gwynne and Dadour 1985; Maddison and Stratton 1988; Jackson and Pollard 1997; Noordam 2002; Elias et al. 2003, 2005, 2010, 2012; Sivalinghem et al. 2010). Salticids are also known to make extensive use of chemoreception. Examples include experiments showing that salticids can use chemoreception for discriminating between conspecific and heterospecific individuals, familiar and unfamiliar rivals and own and other conspecific individuals' eggs and draglines, as well as determining whether a potential mate is reproductively mature, determining what a potential mate has been eating and even determining the fighting ability of a rival (Jackson 1987; Pollard et al. 1987; Clark and Jackson 1994a, b, 1995a, b; Taylor 1998; Clark et al. 1999; Cross et al. 2009; Jackson and Cross 2011a, b). Moreover, some salticid species are known to escalate conflict with conspecific rivals when they detect odour from potential mates (Cross et al. 2007; Cross and Jackson 2009b), whilst others are proficient at using chemoreception for identifying their preferred prey (Clark et al. 2000a, b; Jackson et al. 2002, 2005). However, with most salticid species used in research pertaining to chemoreception, whether the spider used chemotactile or olfactory pheromones, or both, has been uncertain because the testing design adopted did not prevent contact with the stimulus source. Currently, there are only five salticid species for which the experimental design have provided evidence of specifically olfactory pheromones being used (Willey and Jackson 1993; Cross and Jackson 2009a; Jackson and Cross 2011b).

Here our objective is to investigate the ability of C. algerina and $C$. ocellata to use specifically olfactory pheromones for species and sex identification. That these species might be especially likely to use olfactory pheromones is suggested by their microhabitats. Salticids are typically found in the open where, even if in dense forest, the ambient light level is conducive to seeing detail. However, C. algerina and C. ocellata normally encounter prey and conspecific individuals under and around the lower edges of stones on the ground (Jackson and Hallas 1986; Jackson 1990; Guseinov et al. 2004; Cerveira and Jackson 2011), a structurally complex and dimly lit microhabitat where proficiency at using olfaction could be especially advantageous.
Taxonomic considerations also suggest that use of olfactory pheromones by $C$. algerina and $C$. ocellata is likely. Cyrba belongs to the subfamily, Spartaeine, widely regarded as being a basal clade in the family Salticidae (Maddison and Hedin 2003; Su et al. 2007), and to which four (Jackson and Cross 2011b) of the five species known to use olfactory pheromones belong. It is also of note that Cyrba, along with four other spartaeine genera (Portia, Cocalus, Gelotia and Mintonia) are characterised by having mytiliform organs, situated in clusters of 35-50, and located on the spider's dorsal abdomen and though to function as a source of pheromones (Wanless 1984).

\section{Materials and methods}

Standard spider-laboratory rearing and testing procedures were adopted (see Jackson and Hallas 1986; Cerveira and Jackson 2011). All test spiders were taken from laboratory cultures (2nd and 3rd generation; origin for C. algerina Sintra, Portugal; for $C$. ocellata Mbita Point, Kenya). After dispersal from the egg sac, spiders were kept individually in an enriched environment (see Carducci and Jakob 2000): a spacious cage fitted with a cardboard harmonium provided adequate substrate for nest building and hunting.

All testing was carried out between 0800 and 1200 hours (laboratory photoperiod 12L:12D, lights on 0700 hours). None of the spiders had prior encounters with other salticids. For standardization, all test and source spiders were unmated adults that had matured 2-3 weeks before testing, and all test and source spiders were kept without food for 4-5 days before testing.

Testing was carried out using a Y-shaped olfactometer (Fig. 1) with air pushed by a pump independently into two chambers: a stimulus chamber and a control chamber. Whether the stimulus chamber was on the left or the right was determined at random. There was an odour source in the stimulus but not in the control chamber. Using Matheson FM-1000 flow meters, airflow was adjusted to $1500 \mathrm{ml} / \mathrm{min}$, and there was no evidence that this airflow setting impaired locomotion or had any adverse effects on the test spider's behaviour. Each chamber was a glass tube (length $90 \mathrm{~mm}$, inner diameter $15 \mathrm{~mm}$, each end plugged by a rubber stopper). Smaller glass tubes (length $45 \mathrm{~mm}$, diameter $4 \mathrm{~mm}$ ) that passed through a hole in each stopper, and silicone tubing, connecting these glass tubes to each other and to the pump, allowed air to move through the olfactometer. For confining spiders, there was a nylonnetting screen over the inner side of each stopper, with new netting being used for each trial. From the control and stimulus chambers, air moved independently into the two arms of the Y (i.e. the control and the stimulus arm). 


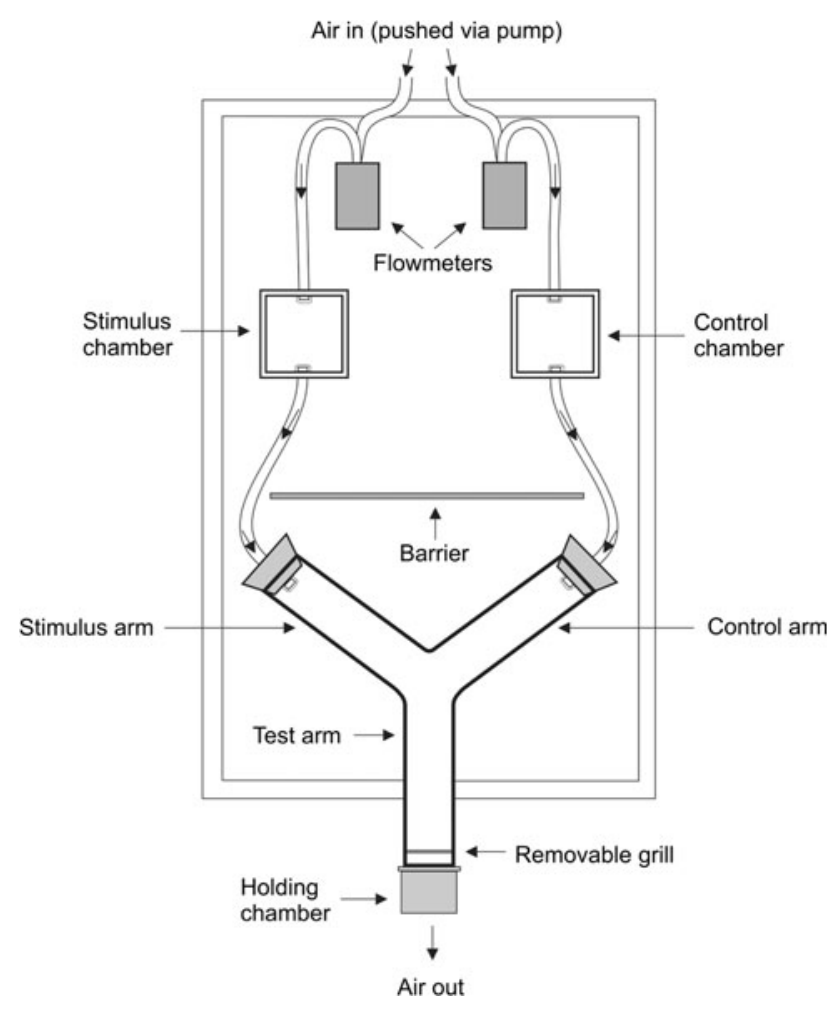

Fig. 1 Olfactometer (not drawn to scale) used for testing Cyrba algerina and C. ocellata. Arrows indicate direction of airflow. Holding chamber (location of test spider at start of test). Start of test: test spider in holding chamber; grill removed, giving access to test arm, control arm and stimulus arm. Opaque barriers block test spider's view of odour source

Since previous research (Cerveira and Jackson 2011) indicated that testing C. algerina and C. ocellata under bright, direct lighting is problematic, we placed the olfactometer inside a cardboard box (length $500 \mathrm{~mm}$, width $500 \mathrm{~mm}$, height $500 \mathrm{~mm}$ ), with the interior being made accessible by a window (width $150 \mathrm{~mm}$, height $150 \mathrm{~mm}$ up from floor, top of window $350 \mathrm{~mm}$ from top of box) cut out of the front end of the box.

Before testing began, the test spider was confined for 2 min to the holding chamber at the far end of the test arm. A metal grill that fitted into a slit in the chamber's roof blocked the test spider's access to the rest of the olfactometer. The grill was lifted to start a test. Once the spider left the holding chamber, it was given $30 \mathrm{~min}$ in which to make a choice, the test spider's 'choice' being defined as the arm of the $\mathrm{Y}$ it entered and stayed in for $30 \mathrm{~s}$. During testing the test spider could not see or touch the odour source.

Individual spiders from both sexes of the two Cyrba species were used in experiments as odour sources. Whenever there was olfactometer evidence that a given odour elicited a response, we also used the draglines of individual spiders (spider absent) as odour sources. The odour source (spider or draglines) was put in the experimental chamber 15 min before testing began.

For collecting draglines, we used a glass Petri dish (diameter $60 \mathrm{~mm}$ ) with a circle of blotting paper (diameter $60 \mathrm{~mm}$ ) covering the inside bottom of the dish and another circle $(60 \mathrm{~mm})$ covering the inside top. At 0700 hours, the source spider was put in the dish, and the dish was then oriented upright and held in place by a clamp so that neither of the two circles of blotting paper was above the other. Blotting paper was held in place on the glass by four squares (each side $10 \mathrm{~mm}$ ) of double-sided sticky tape spaced evenly around the inside perimeter of the dish. On the following day, $15 \mathrm{~min}$ before testing began, the Petri dish was opened, the source spider and sticky tape were removed and one of the two pieces of blotting paper (chosen at random) was rolled up loosely and inserted into the experimental chamber (either on the right or the left side of the olfactometer, decided at random).

As a precaution against the possibility of test spider behaviour being influenced by traces left by spiders used previously as test or source spiders, the olfactometer was dismantled and wiped clean with $80 \%$ ethanol followed by distilled water and then dried between tests. No spider was used as a test spider or source spider more than once. Data from choice testing were analyzed using chi-square tests for goodness of fit (null hypothesis: equal probability of choosing any one arm over the other). Comparisons between odour types were done using chi-square tests for independence.

\section{Results}

Males of both Cyrba species chose the stimulus arm significantly more often than the control arm when the odour source was a conspecific female or the female's draglines, but not when the odour source spider was a heterospecific female or a conspecific male. Females chose none of the odours significantly more often than the no-odour control (Fig. 2).

The number of males that chose the odour of conspecific females did not differ significantly between tests with female spiders present and tests with only the female's draglines present (test of independence; $C$. algerina: $\chi^{2}=$ 1.558, $d f=1, \quad P=0.211, N=40 ;$ C. ocellata: $\chi^{2}=$ $0.173, d f=1, P=0.677, N=40)$.

\section{Discussion}

Our findings show that $C$. algerina and $C$. ocellata males can identify conspecific females on the basis of specifically olfactory stimuli (i.e. reliance on chemotactile stimuli was 
Fig. 2 Results for both sexes of Cyrba algerina and $C$. ocellata tested with Y-shape odour olfactometer (Fig. 1). White bars test spiders that chose stimulus arm. Black bars test spiders that chose control arm (no odour). Odour source in stimulus chamber: $O S C$ opposite-sex conspecific individual, $O S C D$ only the draglines of opposite-sex conspecific individual, $\mathrm{OSH}$ opposite-sex heterospecific individual, SSC same-sex conspecific individual. Chisquare goodness of fit (null hypothesis: experimental arm and control arm chosen equally often). ${ }^{* *} P<0.001$; $* P<0.05 ;{ }^{\mathrm{NS}} P>0.05$
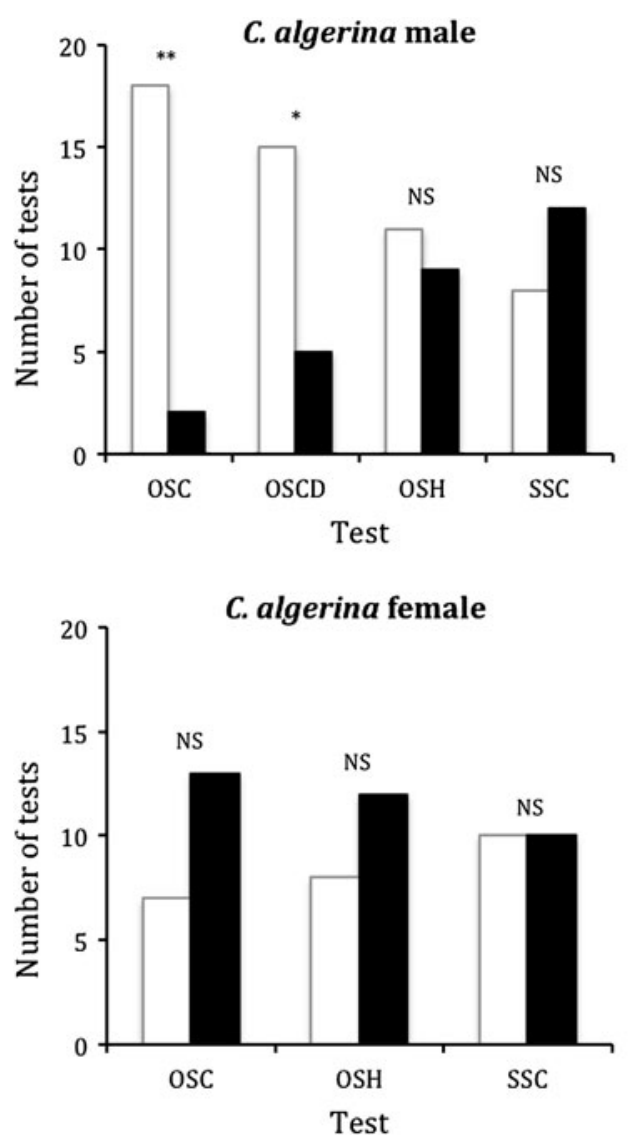
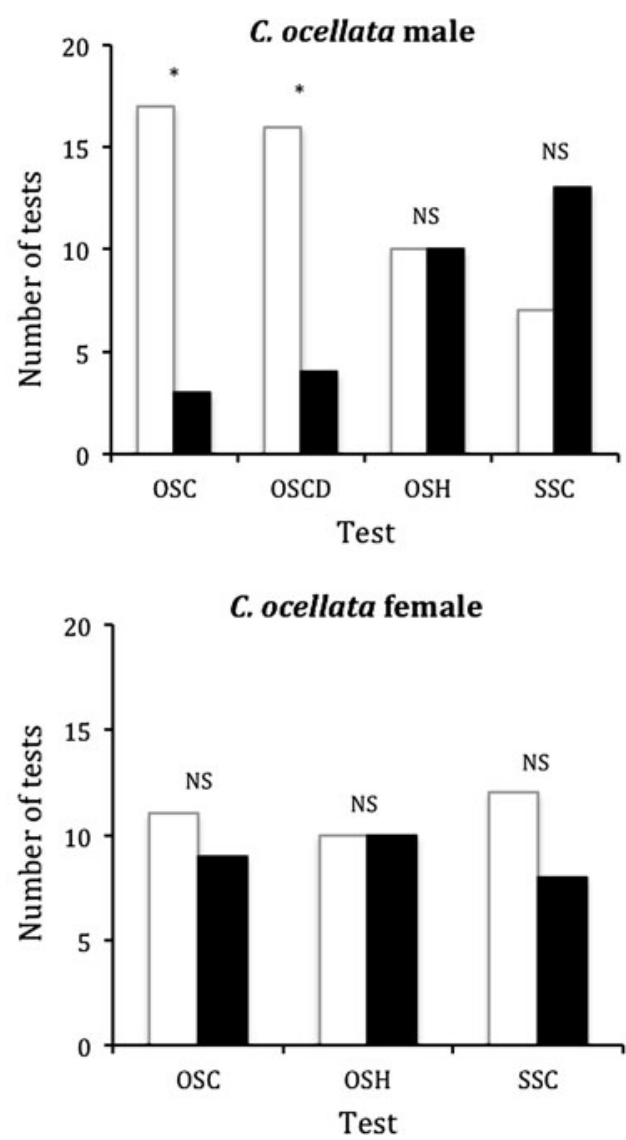

ruled out because our test design prevented contact with the stimulus source). Our findings also show that, even when the female is not present, males respond to olfactory stimuli from the female's draglines. Evidence of draglines functioning as a source of olfactory pheromones may have important methodological implications. It has been traditional to permit contact in experiments aimed at determining whether draglines are pheromone sources (Gaskett 2007), and the spider's response in these experiments is routinely envisaged as being evidence of chemotactile pheromones. Yet the designing of experiments that can clearly distinguish between olfaction and contact chemoreception is a challenging, but rarely acknowledged, problem. Ruling out contact chemoreception when testing for olfaction is comparatively straightforward, but testing for specifically chemotactile pheromones requires more than just allowing for contact. Knowing that silk can be a source of odour, we need to consider the possibility that the spider, even when it can touch the silk, is nonetheless relying on olfactory instead of, or in addition to, chemotactile signals.

Although the sense organs that mediate chemoreception by spiders are not fully understood, tarsal organs (i.e. small pits, or sometimes rods, on the dorsal side of each leg tarsus) appear to function as primary olfactory receptors (Foelix and Chu-Wang 1973; Dumpert 1978; but see Ehn and Tichy 1996), and specialised hairs (tip pore sensilla) on the distal segments of the spider's palps and forelegs appear to function as primary contact chemoreceptors (Foelix 1970; Harris and Mill 1973; Jiao et al. 2011; Tichy et al. 2001). Determining the sense organs that respond to Cyrba pheromones would be of particular interest.

We found no evidence of odour from heterospecific females or conspecific males being relevant to Cyrba males, nor any evidence of any tested odour being relevant to Cyrba females. These findings are consistent with our impression that $C$. algerina and $C$. ocellata follow a common trend among animals (Trivers 1972; Andersson 1994), including salticids (Jackson and Pollard 1997) and other spiders (Huber 2005), of males having a more active role in mate searching and courting, and females placing greater emphasis on active mate choice behaviour.

In this initial study, we standardised spider age and reproductive status (i.e. all test and source spiders were unmated adults that had matured 2-3 weeks before testing). However, as a next step, it would be of interest to determine whether males of $C$. algerina and $C$. ocellata discriminate by olfaction between conspecific females that have and have not already mated. Previously mated Cyrba females sometimes mate again. However, as with many salticids and other spiders (Jackson 1981; Jackson and Pollard 1997; Huber 2005; Cross et al. 2007), prior mating 
seems to make Cyrba females less receptive to courting males, which might, in turn, make previously mated females less attractive to males (see Baruffaldi and Costa 2010). Sperm competition may also predispose males to being less attracted to females that have already mated, as first-male sperm priority appears to be the prevailing pattern when salticid females mate more than once (Jackson 1982; Huber 2005).

With the present study, Cyrba joins Evarcha and Portia (Willey and Jackson 1993; Cross and Jackson 2009a; Jackson and Cross 2011b) as one of only three salticid genera for which there is evidence of species and sex identification on the basis of olfaction alone. However, when spiders can contact silk (draglines or nests), evidence of mate identification exists for many salticid species (Jackson 1987; Clark and Jackson 1995b; Taylor 1998). On this basis it would be tempting to conclude that chemotactile pheromones are more common than olfactory pheromones in the Salticidae. However, as the only published experiments designed specifically for detecting use of olfactory pheromones are those on Cyrba, Evarcha and Portia, this conclusion would be premature.

Acknowledgments We thank Godfrey Otieno Sune, Stephen Abok Aluoch and Jane Atieno Obonyo for their assistance at ICIPE. For a doctoral scholarship (SFRH/BD/8311/2002) to A.M.C. through the European Regional Development Fund, we thank the Fundação para a Ciência e a Tecnologia. We also gratefully acknowledge support of grants from the Royal Society of New Zealand [Marsden Fund (M1096, M1079) and James Cook Fellowship (E5097)] and the National Geographic Society (8676-09, 6705-00).

\section{References}

Aisenberg A, Baruffaldi L, Gonzalez M (2010) Behavioural evidence of male volatile pheromones in the sex-role reversed wolf spiders Allocosa brasiliensis and Allocosa alticeps. Naturwissenschaften 97:63-70

Andersson M (1994) Sexual selection. Princeton University Press, Princeton

Barth FG (2001) A spider's world: senses and behavior. Springer, Berlin

Baruffaldi L, Costa FG (2010) Changes in male sexual responses from silk cues of females at different reproductive states in the wolf spider Schizocosa malitiosa. J Ethol 28:75-85

Blanke R (1972) Nachweis von Pheromonene bei Netzspinnen. Naturwissenschaften 10:481

Bradbury JW, Vehrenchamp SL (2011) Principles of animal communication, 2nd edn. Sinauer Associates, Sunderland

Carde RT, Millar JG (2004) Advances in insect chemical ecology. Cambridge University Press, Cambridge

Carducci JP, Jakob EM (2000) Rearing environment affects behaviour of jumping spiders. Anim Behav 59:39-46

Cerveira AM, Jackson RR (2011) Interpopulation variation in kairomone use by Cyrba algerina, an araneophagic jumping spider from Portugal. J Ethol 29:121-129

Chinta SP, Goller S, Lux J, Funke S, Uhl G, Schulz S (2010) The sex pheromone of the wasp spider Argiope bruennichi. Angew Chem Int Ed 49:2033-2036
Clark RJ, Jackson RR (1994a) Portia labiata, a cannibalistic jumping spider, discriminates between own and foreign eggsacs. Int Comp Psychol 7:38-43

Clark RJ, Jackson RR (1994b) Self recognition in a jumping spider: Portia labiata females discriminate between their own draglines and those of conspecifics. Ethol Ecol Evol 6:371-375

Clark RJ, Jackson RR (1995a) Araneophagic jumping spiders discriminate between the draglines of familiar and unfamiliar conspecifics. Ethol Ecol Evol 7:185-190

Clark RJ, Jackson RR (1995b) Dragline-mediated sex recognition in two species of jumping spiders (Araneae, Salticidae), Portia labiata and P. fimbriata. Ethol Ecol Evol 7:73-77

Clark RJ, Jackson RR, Waas JR (1999) Draglines and assessment of fighting ability in cannibalistic jumping spiders. J Insect Behav 12:753-766

Clark RJ, Jackson RR, Cutler B (2000a) Chemical cues from ants influence predatory behavior in Habrocestum pulex (Hentz), an ant-eating jumping spider (Araneae, Salticidae). J Arachnol 28:299-341

Clark RJ, Harland DP, Jackson RR (2000b) Speculative hunting by an araneophagic salticid spider. Behaviour 137:1601-1612

Cross FR, Jackson RR (2009a) Mate-odour identification by both sexes of Evarcha culicivora, an East African jumping spider. Behav Proc 81:74-79

Cross FR, Jackson RR (2009b) How cross-modality effects during intraspecific interactions of jumping spiders differ depending on whether a female-choice or mutual-choice mating system is adopted. Behav Process 80:162-168

Cross FR, Jackson RR, Pollard SD (2007) Male and female matechoice decisions by Evarcha culicivora, an East African jumping spider. Ethology 113:901-908

Cross FR, Jackson RR, Pollard SD (2009) How blood-derived odor influences mate-choice decisions by a mosquito-eating predator. Proc Natl Acad Sci USA 106:19416-19419

Dumpert K (1978) Spider odor receptors: electrophysiological proof. Cell Mol Life Sci 34:754-756

Edwards GB (1981) Sound production by courting males of Phidippus mystaceus (Araneae: Salticidae). Psyche 88:199-214

Ehn R, Tichy H (1996) Response characteristics of a spider warm cell: temperature sensitivities and structural properties. J Comp Physiol A 178:537-542

Elias DO, Mason AC, Maddison WP, Hoy RR (2003) Seismic signals in a courting male jumping spider (Araneae: Salticidae). J Exp Biol 206:4029-4039

Elias DO, Hebets EA, Hoy RR, Mason AC (2005) Seismic signals are crucial for male mating success in a visual specialist jumping spider (Araneae: Salticidae). Anim Behav 69:931-938

Elias DO, Sivalinghem S, Mason AC, Andrade MCB, Kasumovic MM (2010) Vibratory communication in the jumping spider Phidippus clarus: substrate-borne courtship signals are important for male mating success. Ethology 116:990-998

Elias DO, Maddison WP, Peckmezian C, Girard MB, Mason AC (2012) Orchestrating the score: complex multimodal courtship in the Habronattus coecatus group of Habronattus jumping spiders (Araneae: Salticidae). Biol J Linn Soc 105:522-547

Foelix RF (1970) Chemosensitive hairs in spiders. J Morphol 132: 313-334

Foelix RF (2011) Biology of spiders, 3rd edn. Oxford University Press, Oxford

Foelix RF, Chu-Wang I-W (1973) The morphology of spider sensilla. II. Chemoreceptors. Tissue Cell 5:461-478

Gaskett AC (2007) Spider sex pheromones: emission, reception, structures, and functions. Biol Rev 82:27-48

Guseinov EF, Cerveira AM, Jackson RR (2004) The predatory strategy, natural diet, and life cycle of Cyrba algerina, an 
araneophagic jumping spider (Salticidae: Spartaeinae) from Azerbaijan. N Z J Zool 31:291-303

Gwynne DT, Dadour IR (1985) A new mechanism of sound production by courting male jumping spiders (Araneae: Salticidae, Saitis michaelseni Simon). J Zool (Lond) 207:35-42

Harland DP, Li D, Jackson RR (2012) How jumping spiders see the world. In: Lazareva O, Shimizu T, Wasserman EA (eds) How animals see the world: comparative behavior, biology, and evolution of vision. Oxford University Press, Oxford, pp 133-164

Harris DJ, Mill PJ (1973) The ultrastructure of chemoreceptor sensilla in Ciniflo (Araneida, Arachnida). Tissue Cell 5:679-689

Huber BA (2005) Sexual selection research on spiders: progress and biases. Biol Rev 80:363-385

Jackson RR (1981) Relationship between reproductive security and intersexual selection in a jumping spider, Phidippus johnsoni (Araneae: Salticidae). Evolution 35:601-604

Jackson RR (1982) The behavior of communicating in jumping spiders (Salticidae). In: Witt PN, Rovner JS (eds) Spider communication: mechanisms and ecological significance. Princeton University Press, Princeton, pp 213-247

Jackson RR (1987) Comparative study of releaser pheromones associated with the silk of jumping spiders (Araneae, Salticidae). N Z Zool 14:1-10

Jackson RR (1990) Predatory versatility and intraspecific interactions of Cyrba algerina and C. ocellata, web-invading spartaeine jumping spiders (Araneae, Salticidae). N Z J Zool 17:157-168

Jackson RR, Cross FR (2011a) Spider cognition. Adv Insect Physiol 41:115-174

Jackson RR, Cross FR (2011b) Olfaction-based mate-odor identification by jumping spiders from the genus Portia. J Arachnol 39:439-443

Jackson RR, Hallas SEA (1986) Predatory versatility and intraspecific interactions of spartaeine jumping spiders (Araneae: Salticidae): Brettus adonis, B. cingulatus, Cyrba algerina and Phaeacius sp. indet. N Z J Zool 13:491-520

Jackson RR, Pollard SD (1997) Jumping spider mating strategies: sex among cannibals in and out of webs. In: Choe JC, Crespi BJ (eds) The evolution of mating systems in insects and arachnids. Cambridge University Press, Cambridge, pp 340-351

Jackson RR, Clark RJ, Harland DP (2002) Behavioural and cognitive influences of kairomones on an araneophagic spider. Behaviour 139:749-775

Jackson RR, Nelson XJ, Sune GO (2005) A spider that feeds indirectly on vertebrate blood by choosing female mosquitoes as prey. Proc Natl Acad Sci USA 102:15155-15160

Jerhot E, Stoltz JA, Andreade MCB, Schulz S (2010) Acylated serine derivatives: a unique class of arthropod pheromones of the Australian redback spider, Latrodectus hasselti. Angew Chem Int Ed 49:2037-2040

Jiao X, Chen Z, Du H, Chen J, Lu F (2011) Chemoreceptors distribution and relative importance of male forelegs and palps in intersexual chemical communication of the wolf spider Pardosa astrigera. Chemoecology 21:45-49

Land MF, Nilsson DE (2002) Animal eyes. Oxford University Press, Oxford

Maddison WP, Hedin M (2003) Jumping spider phylogeny (Araneae: Salticidae). Invert Syst 17:529-549

Maddison WP, Stratton GE (1988) Sound production and associated morphology in male jumping spiders of the Habronattus agilis species group (Araneae: Salticidae). J Arachnol 16:199-211
Maynard Smith J, Harper D (2003) Animal signals. Oxford University Press, Oxford

Noordam AP (2002) Abdominal percussion and ventral scutum in male Euophrys frontalis (Araneae: Salticidae). Entomol Ber Amsterdam 62:17-19

Papke M, Schulz S, Tichy H, Gingl E, Ehn R (2000) Identification of a new sex pheromone from the silk dragline of the tropical wandering spider Cupiennius salei. Angew Chem Int Ed 39:4339-4341

Papke MD, Riechert SE, Schulz S (2001) An airborne female pheromone associated with male attraction and courtship in a desert spider. Anim Behav 61:877-886

Pollard SD, Macnab AM, Jackson RR (1987) Communication with chemicals: pheromones and spiders. In: Nentwig W (ed) Ecophysiology of spiders. Springer, Heidelberg, pp 133-141

Schulz S, Toft S (1993) Identification of a sex-pheromone from a spider. Science 260:1635-1637

Searcy LE, Rypstra AL, Persons MH (1999) Airborne chemical communication in the wolf spider Pardosa milvina. J Chem Ecol $25: 2527-2533$

Shorey HH (1976) Animal communication by pheromones. Academic, New York

Sivalinghem S, Kasumovic MM, Mason AC, Andrade MCB, Elias DO (2010) Vibratory communication in the jumping spider Phidippus clarus: polyandry, male courtship signals, and mating success. Behav Ecol 21:1308-1314

Steiger S, Schmitt T, Schaefer HM (2011) The origin and dynamic evolution of chemical information transfer. Proc R Soc B 278:970-979

Su KF, Meier R, Jackson RR, Harland DP, Li D (2007) Convergent evolution of eye ultrastructure and divergent evolution of visionmediated predatory behaviour in jumping spiders. J Evol Biol 20:1478-1489

Symonds MRE, Elgar MA (2008) The evolution of pheromone diversity. Trends Ecol Evol 23:220-228

Taylor PW (1998) Dragline-mediated mate-searching in Trite planiceps (Araneae, Salticidae). J Arachnol 26:330-334

Tichy H, Gingl E, Ehn R, Papke M, Schulz S (2001) Female sex pheromone of a wandering spider (Cupiennius salei): identification and sensory reception. J Comp Physiol A 187:75-78

Trabalon M, Bagnères A-G (2010) Contact recognition pheromones in spiders and scorpions. In: Blomquist GJ, Bagnères A-G (eds) Insect hydrocarbons: biology, biochemistry, and chemical ecology. Cambridge University Press, Cambridge, pp 344-374

Trivers RL (1972) Parental investment and sexual selection. In: Campbell B (ed) Sexual selection and the descent of man. Aldine, Chicago, pp 136-179

Wanless FR (1984) A review of the spider subfamily Spartaeinae nom.n. (Araneae: Salticidae) with descriptions of six new genera. Bull Br Mus Nat Hist (Zool) 46:135-205

Willey MB, Jackson RR (1993) Olfactory cues from conspecifics inhibit the web-invasion behaviour of Portia, a web-invading, araneophagic jumping spider (Araneae, Salticidae). Can J Zool 71:415-1420

Wyatt TD (2003) Pheromones and animal behaviour. Cambridge University Press, Cambridge

Xiao YH, Zhang JX, Li SQ (2010) Male-specific (Z)-9-tricosene stimulates female mating behaviour in the spider Pholcus beijingensis. Proc R Soc B 277:3009-3018 